\title{
Activity Coefficients in Aqueous Mixtures of Phosphates with Sodium Chloride, Sodium Bromide, and Sodium Iodide, and the $\mathrm{pH}$ of Phosphate Buffer Solutions
}

\author{
By Roger G. Bates
}

\begin{abstract}
The electromotive force of cells with hydrogen electrodes and silver-silver bromide or silver-silver iodide electrodes was measured at $25^{\circ} \mathrm{C}$. The electrolyte in each cell consisted of an aqueous mixture of (a) potassium dihydrogen phosphate, (b) disodium hydrogen phosphate, and (c) sodium bromide or sodium iodide. The molalities of (a) and (b) were always equal, whereas the ratio of the molality of (c) to that of (a) or (b) was 1, 0.5, or 0.2. The ionic strengths ranged from 0.04 to 0.25 . The data are compared with similar measurements for phosphate-chloride mixtures reported in an earlier paper. At a given ionic strength, the activity-coefficient term, $f_{\mathrm{H}_{2} \mathrm{PO}_{4}} f_{\mathrm{X}} / f_{\mathrm{HPO}_{4}}$ where $X$ represents halide, increases when bromide at a given concentration is substituted for chloride at the same concentration, or when iodide replaces bromide. Accurate values for the $\mathrm{pH}$ of phosphate buffer solutions with and without added salt can be obtained only at low ionic strengths.
\end{abstract}

\section{Introduction}

During the past several years, methods for determining activity $\mathrm{pH}\left(-\log \mathbf{a}_{\mathrm{H}}\right)$ for standard buffer solutions from electromotive-force measurements of cells without liquid junction have been developed. These methods have been used to assign $\mathrm{pH}$ values to certain phosphate, phthalate, and borate solutions prepared from Standard Samples certified by the National Bureau of Standards $[1,2,3] .{ }^{1}$ Cells with hydrogen and silver-silver chloride electrodes were employed in each instance. The electromotive-force data for aqueous mixtures of the buffers with sodium or potassium chloride afford an unequivocal determination of $-\log \mathbf{a}_{\mathrm{H}} f_{\mathrm{Cl}}$, where $f_{\mathrm{C} 1}$ is the activity coefficient of chloride ion ${ }^{2}$ for each solution studied. Furthermore, the value of this quantity in a buffer solution without chloride can be ascertained by a suitable extrapolation from a series of determinations in which the molal

\footnotetext{
Figures in brackets indicate the literature references at the end of this paper.

${ }^{2}$ The molal scale of activity is used throughout this paper. The so-called "activity $\mathrm{pH}$ ", $-\log$ aH, will be designated $\mathrm{paH}$, in accordance with the suggestion of Sørensen and Linderstrøm-Lang [4]. Concentrations will be given in molality $(m)$. The symbol $\mu$ is used for ionic strength.
}

ratio of chloride to buffer is varied. It is impossible to derive $-\log \mathbf{a}_{\mathrm{H}}$ from these measurable quantities without an estimate of $f_{\mathrm{Cl}}$, and the evaluation of this ionic activity coefficient must rest partly upon arbitrary considerations. It must be realized that paH computed from the emf of cells without liquid junction is primarily a unit on an arbitrary scale, as is that determined by the usual $\mathrm{pH}$ assembly with a liquid junction $[5,6]$. Its significance in terms of thermodynamic constants may be limited to a small number of standard solutions of assigned paH and may not be imparted to mixtures of unknown composition whose paH it is desired to determine.

The chloride ion plays a unique and important role in the derivation of $\mathrm{paH}$ from the emf of the hydrogen-silver chloride cell without junction. However reasonable the assumptions involved in the computation may appear, their validity can usually not be affirmed. Hence, it is important to demonstrate the extent to which the properties of chloride ion, and of the silver-silver chloride electrode, influence the paH of the buffer solution without chloride obtained by these means. For this purpose, equimolal mixtures of potassium 
dihydrogen phosphate and disodium hydrogen phosphate were chosen. The paH of these solutions has already been calculated from measurements of $-\log \mathbf{a}_{\mathrm{H}} f_{\mathrm{Cl}}$ in mixtures of the phosphate buffer with varying amounts of sodium chloride [1]. Sodium bromide and sodium iodide were added to equimolal phosphate buffers in such amounts that the ratios of the molality of halide to that of each phosphate had the three values $1,0.5$, and 0.2 . Measurements of the emf of hydrogen-silver bromide and hydrogen-silver iodide cells, with these phosphate-halide mixtures as cell solutions, were made at $25^{\circ} \mathrm{C}$. The assumptions were tested by computing the paH of the phcsphate buffer, in the absence of added salt, from the three series of emf data.

\section{Determination of the Activity Coefficients}

The cells used in this study can all be represented by the following scheme,

$$
\begin{gathered}
\text { Pt; } \mathrm{H}_{2}(\mathrm{~g}, 1 \mathrm{~atm}), \mathrm{KH}_{2} \mathrm{PO}_{4}\left(m_{1}\right), \mathrm{Na}_{2} \mathrm{HPO}_{4}\left(m_{1}\right), \\
\mathrm{NaX}\left(m_{2}\right), \mathrm{AgX}(s) ; \mathrm{Ag},
\end{gathered}
$$

where $\mathrm{X}$ is chlcride, bromide, or iodide, and $m$ is molality. When the standard potential, $E^{\circ}$, of the cell is known, $-\log \mathbf{a}_{\mathrm{H}} f_{\mathrm{X}}$ is readily obtained from the emf, $E$, and natural constants:

$$
-\log \mathbf{a}_{\mathrm{H}} f_{\mathrm{X}}=-\log \left(f_{\mathrm{H}} f_{\mathrm{X}} m_{\mathrm{H}}\right)=\frac{\left(E-E^{\circ}\right) \mathbf{F}}{2.3026 R T}+\log m_{\mathrm{X}} .
$$

In eq $1, \mathbf{F}$ is the faraday, $R$ the gas constant, and $T$ the absolute temperature. By substitution of the equilibrium constant for the second dissociation of phosphoric acid in eq 1, we obtain an equation for the activity-coefficient term, designated $\log f_{\tau}$,

$$
\begin{aligned}
\log f_{r} \equiv \log \frac{f_{\mathrm{H}_{2} \mathrm{PO}_{4}} f_{\mathrm{X}}}{f_{\mathrm{HPO}_{4}}}=\mathrm{p} K-\frac{\left(E-E^{\circ}\right) \mathbf{F}}{2.3026 R T}-\log m_{\mathrm{X}} \\
-\log \frac{m_{\mathrm{H}_{2} \mathrm{PO}_{4}}}{m_{\mathrm{HPO}_{4}}}
\end{aligned}
$$

where $\mathrm{p} K$ is the common logarithm of the reciprecal of $K$, the second dissociation constant $[1,7]$. In all of the phosphate buffers to be discussed, the last term of eq 2 is zero.

\section{Experimental Procedures}

Preparation of the equimolal mixture of solid potassium dihydrogen phosphate and disodium hydrogen phosphate was described by Bates and Acree [1]. Sodium bromide was recrystallized three times from water and was dried at $200^{\circ}$ to $300^{\circ} \mathrm{C}$. The dry product was found to be neutral. Sodium iodide was recrystallized twice from water and dried in vacuum at $50^{\circ} \mathrm{C}$ for 1 to 2 days. Filters of sintered glass were used in each instance for separating the crystals from the saturated solution.

Silver-silver bromide electrodes were made as described by Keston [8]. However, the paste of silver oxide and silver bromate was decomposed at $550^{\circ} \mathrm{C}$ instead of at $650^{\circ} \mathrm{C}$. Silver bromate was prepared from sodium bromate and silver nitrate. It was recrystallized from hot water. Silver-silver iodide electrodes were formed on platinum spirals by thermal decomposition, at $450^{\circ}$ $\mathrm{C}$, of a paste composed of 90 percent of silver oxide and 10 percent of silver iodide by weight [9]. Silver iodide, prepared from silver nitrate and recrystallized potassium iodide, was washed 40 times with water and digested at $70^{\circ} \mathrm{C}$ under water for 2 days. Hydrogen electrodes were made by deposition of platinum black on platinum foils sealed in glass. A 3-percent solution of chloroplatinic acid that contained a small amount of lead acetate was used, and the electrolysis was continued for 3 minutes at a current of 250 to 300 ma. Electrodes were always used in pairs and were freshly made for each cell.

The solutions were prepared by weight methods, and nitrogen was passed through them to remove air. Details of the cells and of a part of the equipment are given in an earlier publication [7]. Some of the temperature measurements were made with a platinum resistance thermometer and the rest with a calibrated mercury thermometer. The temperature was regulated within \pm 0.03 $\operatorname{deg} \mathrm{C}$.

The titration cell already described [10] was used for a part of the measurements made with hydrogen and silver-silver bromide electrodes. For this purpose, "semimicro" silver-silver bromide electrodes were prepared. The mixture of silver and silver bromide on each electrode weighed 15 to $20 \mathrm{mg}$. The cell was immersed in the constant-temperature bath and a known 
amount of buffer-bromide mixture added. When the emf had become constant, usually in about 2 hours, a measured portion of air-free water was introduced from the burette. Occasionally a second dilution was made. The emf data for the seven solutions prepared by dilution within the cell are not considered to be as accurate as the rest. These measurements are therefore marked for identification in the table of results given in the next section.

The measuring equipment was checked in two ways. The potentiometer was connected with another similar instrument in the same laboratory, and the emf of a cell was occasionally measured by both instruments. The two values always agreed within $0.02 \mathrm{mv}$. The potentiometers and standard cells had been calibrated by this Bureau. The second method offered a comparison of the silver-silver chloride electrodes with those of Harned and Ehlers [11], for which the standard potential of this electrode was derived. It furnished, as well, an additional check upon the temperature control and on the accuracy of the potentiometer. The emf of three hydrogensilver chloride cells that contained $0.09931 \mathrm{~m}$ of hydrochloric acid was measured and found to be $0.35272 \pm 0.00002 \mathrm{v}$ at $25^{\circ} \mathrm{C}$. This value is identical with that obtained by interpolation in the data of Harned and Ehlers.

\section{Results and Calculations}

The experimental data are summarized in tables 1 and 2 . Values of $-\log \left(f_{\mathrm{H}} f_{\mathrm{X}} m_{\mathrm{H}}\right)$, where $\mathrm{X}$ represents either bromide or iodide, are given in the last columns. They were calculated from the emf by eq 1 .

The standard potential, $E^{\circ}$, of the hydrogensilver bromide cell was taken to be $0.07128 \mathrm{v}$ at $25^{\circ} \mathrm{C}$ [12]. For the hydrogen-silver iodide cell, the emf data of table 2, together with $\mathrm{p} K=7.198$ $[1,7]$, yield, by the method of Owen [13], -0.15201 $\mathrm{v}$ for $E^{\circ}$. This potential was used in the subsequent computations. Owen [13] found -0.15225 for the same cell with silver-silver iodide electrodes formed by the thermal decomposition of a mixture of silver oxide and silver iodate. Gould and Vosburgh [14], however, obtained -0.1519. Their electrodes were of the same type as those used in this investigation.

Values of $-\log \left(f_{\mathrm{H}} f_{\mathrm{X}} m_{\mathrm{H}}\right)$ for solutions that contained sodium bromide and sodium iodide at a
TABLE 1. Emf of the cell, $\mathrm{Pt} ; \mathrm{H}_{2}$ (1 atm), $\mathrm{KH}_{2} \mathrm{PO}_{4}\left(x m_{1}\right)$, $\mathrm{Na}_{2} \mathrm{HPO}_{4}\left(x m_{1}\right), \mathrm{NaBr}\left(x m_{2}\right), \operatorname{AgBr}(s) ; \mathrm{Ag}$, at $25^{\circ} \mathrm{C}$; values of $-\log \left(f_{\mathrm{H}} f_{\mathrm{Br}} m_{\mathrm{H}}\right)$

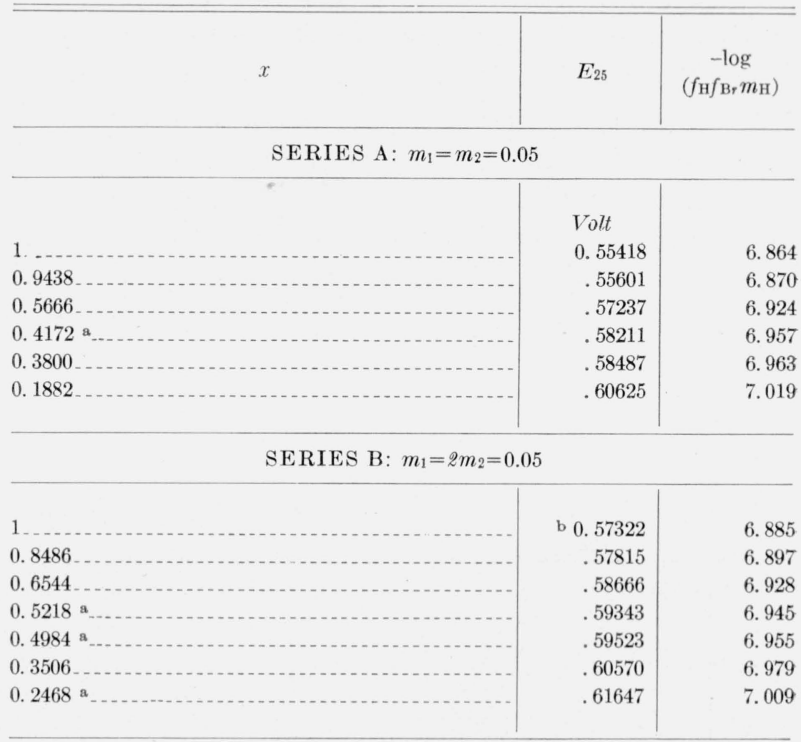

SERIES C: $m_{1}=5 m_{2}=0.05$

\begin{tabular}{ll|r|r}
\hline $1 \ldots$ & \\
0.8070 & 0.59731 & 6.895 \\
$0.6600 \mathrm{a}$ & .60417 & 6.918 \\
0.5240 & .61051 & 6.937 \\
$0.4922^{\mathrm{a}}$ & .61754 & 6.956 \\
$0.4316 \mathrm{a}^{\mathrm{a}}$ & .61966 & 6.965 \\
& .62338 & 6.971
\end{tabular}

a Dilution made in a titration cell.

b Average of two cells. Mean deviation, $0.09 \mathrm{mv}$.

c Average of three cells. Mean deviation, $0.04 \mathrm{mv}$.

TABLE 2. Emf of the cell, $\mathrm{Pt} ; \mathrm{H}_{2}$ (1 atm), $\mathrm{KH}_{2} \mathrm{PO}_{4}\left(x m_{1}\right)$, $\mathrm{Na}_{2} \mathrm{HPO}_{4}\left(x m_{1}\right)$, NaI $\left(x m_{2}\right), \mathrm{AgI}(s) ; \mathrm{Ag}$, at $25^{\circ} \mathrm{C}$; values of $-\log \left(f_{\mathrm{H}} f_{\mathrm{I}} m_{\mathrm{H}}\right)$

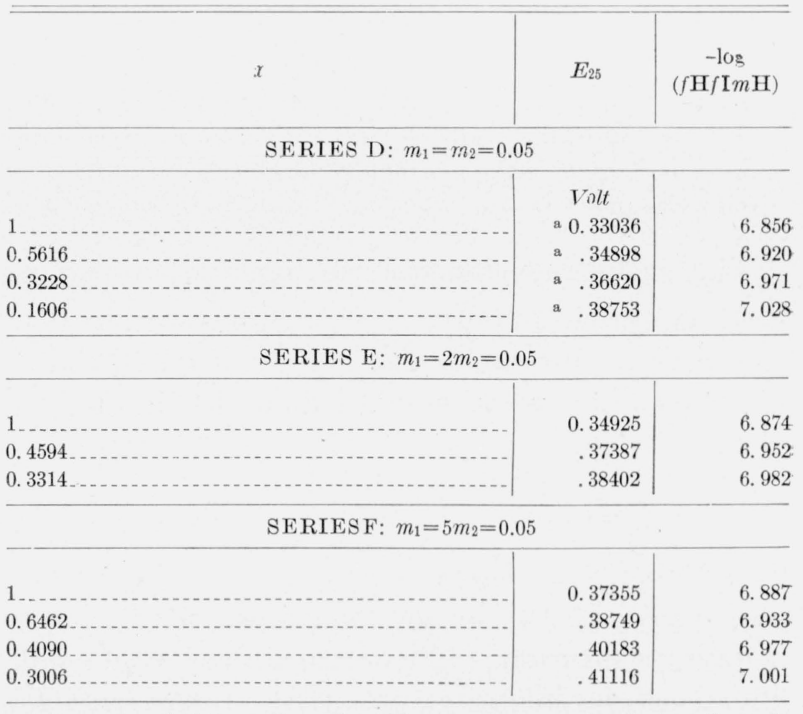

a Average emf of two cells. The differences between duplicate cells made from these four solutions were $0.07,0.17,0.07$, and $0.04 \mathrm{mv}$. 
molality equal to that of each phosphate salt are compared with similar data for phosphate-chloride mixtures [1] in figure 1. When the three curves, plotted from measurements at sufficiently high concentrations that the buffer ratio was always unity, are extended to zero ionic strength, they meet at 7.198 , the value of $\mathrm{p} K$ at $25^{\circ} \mathrm{C}$. The separation of these three curves at a given ionic strength decreases as the ratio of halide to phosphate decreases, but the curves fail to meet, if the ionic strength exceeds 0.05 , even at zero concentration of halide.

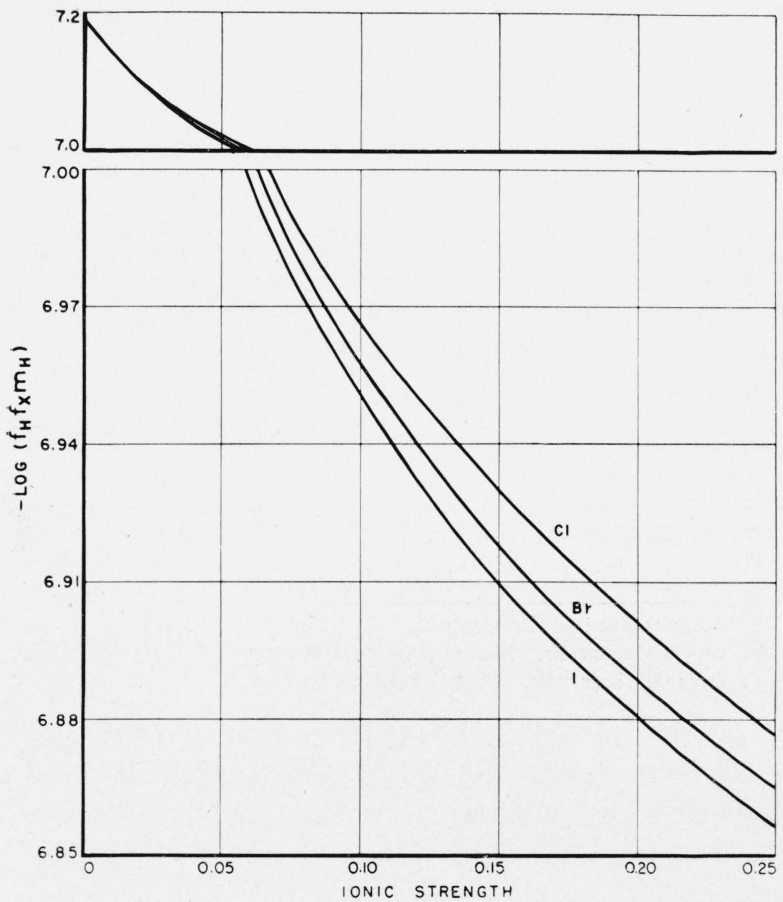

Figure 1. Values of $-\log \left(f_{\mathrm{H}} f_{\mathrm{X}} m_{\mathrm{H}}\right)$ in equimolal phosphate buffers containing sodium halide $(\mathrm{NaX})$ at a molatity equal to that of each phosphate, plotied as a function of ionic strength.

The activity-coefficient term, $\log \left(f_{\mathrm{H}_{2} \mathrm{PO}_{4}} f_{\mathrm{X}} / f_{\mathrm{HPO}_{4}}\right)$, was computed by eq 2 . The values obtained in this manner for each ratio of bromide and iodide to phosphate were smoothed with the aid of plots of $P$, defined by

$$
P \equiv \log f_{r}-1.017 \sqrt{\mu} /(1+1.31 \sqrt{\mu}),
$$

as a function of ionic strength, $\mu$. These lines were drawn to the origin, inasmuch as $P$ is zero at infinite dilution. Their curvatures were small. The average deviation, $\Delta$, of the "observed" log $f_{r}$ from the smooth curve is given in the next to the last column of table 3 . These deviations, expressed in millivolts, are designated $\Delta^{\prime}$ and are listed in the last column. The value of $\log f_{r}$ in phosphate buffer solutions with varying amounts of sodium chloride, sodium bromide, or sodium iodide, and in buffer solutions without halide $\left(\log f_{r}^{\circ}\right)$, is given in table 4 . Log $f_{r}$ in mixtures

TABLE 3. Smoothing of $\log f_{r}$

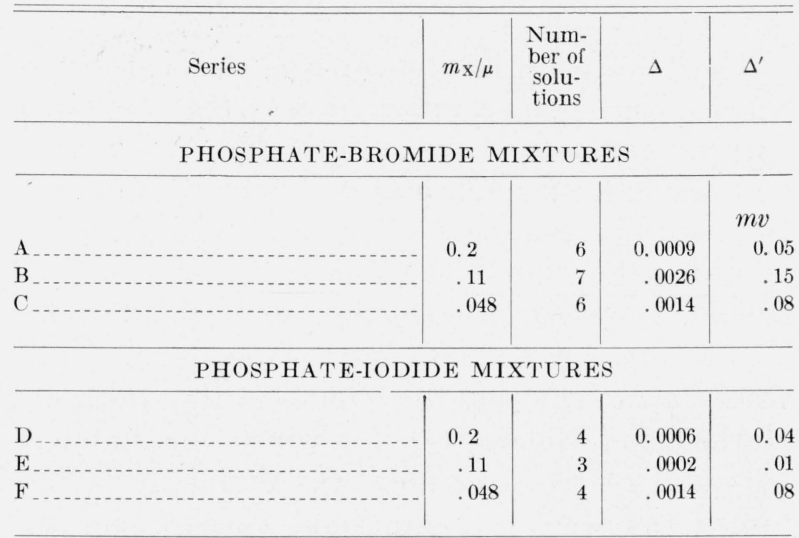

TABLE 4. $\log f_{r}, \log f_{r}^{\circ}$, and $-\log \left(f_{\mathrm{H}} f_{\mathrm{X}} m_{\mathrm{H}}\right)^{\circ}$ for phosphate buffer solutions

\begin{tabular}{|c|c|c|c|c|c|}
\hline \multirow{2}{*}{ Ionic strength } & \multicolumn{3}{|c|}{$\log f_{r}$ when $m_{\mathrm{NaX}} / \mu$ is- } & \multirow{2}{*}{$\log f_{r}^{\circ}$} & \multirow{2}{*}{$\begin{array}{l}-\log \\
\left(f_{\mathrm{H} f \mathrm{X}}\right. \\
\left.m_{\mathrm{H}}\right)^{\circ}\end{array}$} \\
\hline & 0.2 & 0.11 & 0.048 & & \\
\hline \multicolumn{6}{|c|}{$\mathrm{X}=\mathrm{Cl}$} \\
\hline 0.01 & & & & 0.089 & 7. 109 \\
\hline .05 & 0.1770 & 0.1760 & a 0.1749 & .1748 & 7.023 \\
\hline .07 & .2018 & .2004 & .1989 & .1983 & 7. 000 \\
\hline $.1 \ldots$ & .2310 & .2290 & .2268 & .2263 & 6. 972 \\
\hline .15 & .2679 & .2649 & .2616 & .2610 & 6. 937 \\
\hline $.20^{\circ}$ & .2968 & .2926 & .2884 & .2870 & 6. 911 \\
\hline $.25 \ldots$ & .3209 & .3156 & .3103 & .3084 & 6.890 \\
\hline \multicolumn{6}{|c|}{$\mathrm{X}=\mathrm{Br}$} \\
\hline \multicolumn{4}{|l|}{0.01} & 0.090 & 7. 108 \\
\hline .05 & 0.1818 & 0.1802 & 0.1782 & .1772 & 7. 021 \\
\hline $.07 \ldots$ & .2080 & .2058 & .2035 & .2020 & 6. 996 \\
\hline $.1 \ldots$ & .2391 & .2360 & .2330 & .2310 & 6. 967 \\
\hline $.15 \ldots$ & .2786 & .2739 & .2699 & .2672 & 6. 931 \\
\hline $.20 \ldots$ & .3091 & .3032 & .2986 & .2952 & 6. 903 \\
\hline $.25 \ldots$ & .3340 & .3270 & .3220 & .3183 & 6.880 \\
\hline \multicolumn{6}{|c|}{$\mathrm{X}=\mathrm{I}$} \\
\hline \multicolumn{4}{|l|}{$0.01 \ldots$} & 0.091 & 7.107 \\
\hline .05 & 0.1859 & 0.1836 & 0.1808 & .1790 & 7. 019 \\
\hline .07 & .2132 & .2105 & 2067 & .2048 & 6. 993 \\
\hline $1 \ldots$ & .2453 & .2421 & .2372 & .2350 & 6.963 \\
\hline $.15_{\ldots} \ldots$ & .2857 & .2817 & . 6759 & .2730 & 6.925 \\
\hline $.20 \ldots$ & .3170 & .3116 & .3058 & .3028 & 6.895 \\
\hline $.25 \ldots$ & .3425 & .3357 & .3306 & .3267 & 6. 871 \\
\hline
\end{tabular}

a Values of $\log f_{\mathrm{r}}$ in the phosphate-chloride mixtures are given for $m_{\mathrm{NaCl}} / \mu=$ 0.03 instead of 0.048 
that contained bromide or iodide was read from the smoothed curves and for chloride-phosphate mixtures was taken from data given in the earlier paper [1]. The limiting values, $\log f_{r}^{\circ}$, were obtained from plots of $\log f_{r}$ with respect to $m_{\mathrm{X}} / \mu$, as shown in figure 2. Straight-line extrapolations were used.

The estimated accuracy of the emf of the bromide and iodide cells is about $0.10 \mathrm{mv}$. The combined errors in emf, in choice of the proper standard potentials for these types of electrodes, and in smoothing and extrapolating $\log f_{r}$ require that the limiting quantity, $\log f_{r}^{\circ}$, be assigned uncertainties of \pm 0.002 for the chloride series and \pm 0.003 for the bromide and iodide series.

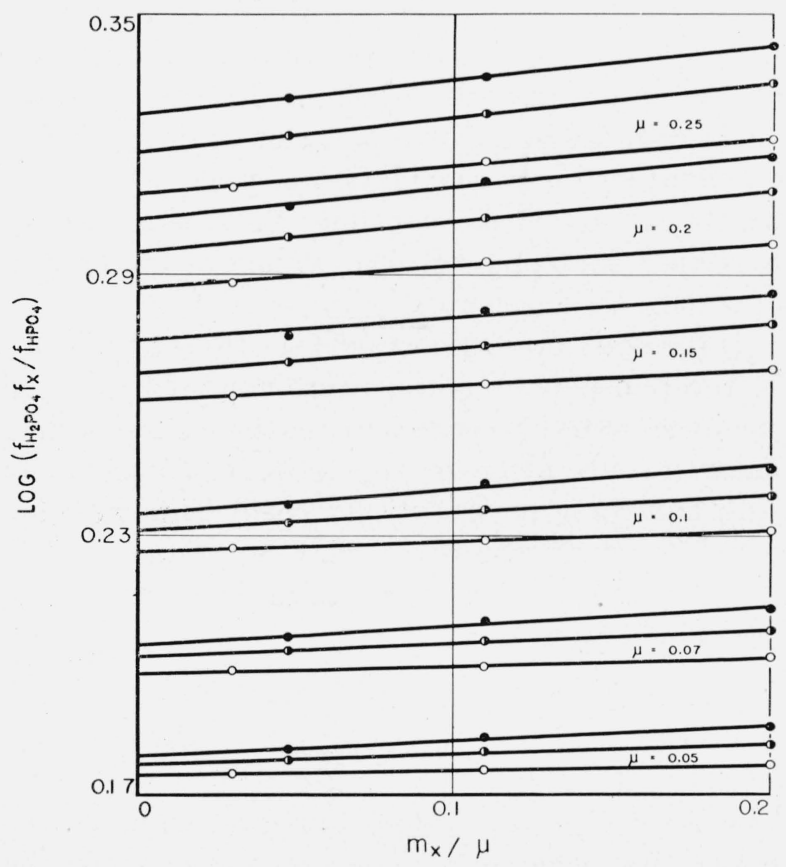

FIGURE 2. $\log \left(f_{\mathrm{H}_{2} \mathrm{PO}_{4}} f_{\mathrm{X}} / f_{\mathrm{HPO}_{4}}\right)$ plotted as a function of the fractional contribution of halide, $\mathrm{NaX}$, to the total ionic strength.

Lower curve of each group: $\mathrm{X}$ is $\mathrm{Cl}$; middle curve: $\mathrm{X}$ is $\mathrm{Br}$; upper curve: $\mathrm{X}$ is $\mathrm{I}$

The last column of table 4 gives the limiting value of $-\log \left(f_{\mathrm{H}} f_{\mathrm{X}} m_{\mathrm{H}}\right)$, when halide is absent, at each ionic strength. Inasmuch as the ratio of the molalities of the two phosphate anions remains unity, $-\log \left(f_{\mathrm{H}} f_{\mathrm{X}} m_{\mathrm{H}}\right)^{\circ}$ is obtained simply by subtraction of $\log f_{r}^{\circ}$ from $\mathrm{p} K$ :

$$
-\log \left(f_{\mathrm{H}} f_{\mathrm{X}} m_{\mathrm{H}}\right)^{\circ}=\mathrm{p} K-\log f_{r}^{\circ}
$$

Equation 4 is readily derived from the mass law and the definition of $f_{r}$ (eq 2).

It is noteworthy that $-\log \left(f_{\mathrm{H}} f_{\mathrm{X}} m_{\mathrm{HI}}\right)^{\circ}$ decreases as $\mathrm{X}$ increases in atomic weight. This change is to be expected if the activity coefficients of the halogen acids at zero concentration in a phosphate solution are in the same order as the mean activity coefficients of the sodium and potassium halides and the halogen acids in their pure aqueous solutions. For the same reason, $\log f_{r}^{\circ}$ increases from chloride to iodide. The employment of these activity coefficients in the estimation of the $\mathrm{paH}$ of phosphate buffer solutions will be considered in the next section.

\section{III. $\mathrm{pH}$ of Phosphate Buffer Solutions}

Bates and Acree [1] found that the change of $\log f_{r}$ with ionic strength for each of the ratios of chloride to phosphate could be represented satisfactorily by an equation of the Hückel [15] type with two adjustable parameters, $a^{*}$ and $\beta^{*}$. Log $f_{r}^{\circ}$ at $25^{\circ} \mathrm{C}$ can be expressed by the equation,

$$
\log f_{r}^{\circ}=\frac{1.017 \sqrt{\mu}}{1+0.3281 a^{\circ} \sqrt{\mu}}+\beta^{\circ} \mu .
$$

The values of $a^{\circ}$ and $\beta^{\circ}$ for the chloride, bromide, and iodide series were determined by fitting log $f_{r}^{\circ}$, given in table 4 , to eq 5 . The parameters, obtained by least-square methods, are listed in table 5. The average difference, $\Delta$, between the "observed" $\log f_{r}^{\circ}$ and that calculated by eq 5 is given in the last column.

TABLE 5. Parameters of eq 5 for $\log \left(f_{\mathrm{H}_{2} \mathrm{PO}_{4}} f_{\mathrm{X}} / f_{\mathrm{HPO}_{4}}\right)$ in

\begin{tabular}{|c|c|c|c|}
\hline & $a^{\circ}$ & $8^{\circ}$ & $\Delta$ \\
\hline $\mathrm{Cl}$ & 4.4 & 0.054 & 0.0002 \\
\hline $\mathrm{Br}$ & 4. 2 & .069 & .0000 \\
\hline I $\ldots \ldots \ldots \ldots$ & 4.0 & .079 & .0003 \\
\hline
\end{tabular}
phosphate buffers without halide

Up to this point, the treatment has remained thermodynamically rigorous. However, an evaluation of $\mathrm{paH}$, or $-\log f_{\mathrm{H}} m_{\mathrm{H}}$, will involve an assumption that is partly arbitrary, as indicated earlier in this paper. The formal mass-law expression for the paH of a phosphate buffer solution, with substitution of the Hückel equation 
for the activity coefficients of the two phosphate anions at $25^{\circ} \mathrm{C}$, can be written as follows,

$$
\mathrm{paH}=\mathrm{p} K-\log \frac{m_{\mathrm{H}_{2} \mathrm{PO}_{4}}}{m_{\mathrm{HPO}_{4}}}-\frac{1.5255 \sqrt{\mu}}{1+0.3281 a \sqrt{\mu}}-\beta \mu .
$$

Bates and Acree assumed that $a^{\circ}$ and $\beta^{\circ}$, the parameters of eq 5 for phosphate buffers without added chloride, could be identified with $a$ and $\beta$ of eq 6, for the same buffer solutions. ${ }^{3}$ The validity of this assumption is not subject to experimental proof, but a partial test can be obtained through a comparison of the $\mathrm{paH}$ derived in this manner from emf measurements made with the three different halide electrodes. The results of these calculations are given in the first half of table 6. At 0.25 , the highest ionic strength studied, the paH values derived from measurements of the chloride and iodide cells differ by 0.025 unit.

It is evident from a comparison of paH with $-\log \left(f_{\mathbf{H}} f_{\mathbf{X}} m_{\mathbf{H}}\right)^{\circ}$ given in table 4 that the normal

TABLE 6. paH of phosphate buffer mixtures: $\mathrm{KH}_{2} \mathrm{PO}_{4}\left(m_{1}\right)$, $\mathrm{Na}_{2} \mathrm{HPO}_{4}\left(m_{1}\right), \mathrm{NaX}\left(m_{2}=0\right)$, from the emf of cells without liquid junction at $25^{\circ} \mathrm{C}$

\begin{tabular}{|c|c|c|c|c|}
\hline \multirow{2}{*}{$m_{1}$. } & \multirow{2}{*}{$\begin{array}{l}\text { Ionic } \\
\text { strength }\end{array}$} & \multicolumn{3}{|c|}{$\mathrm{paH}$ when $\mathrm{X}$ is- } \\
\hline & & Chloride & Bromide & Iodide \\
\hline \multicolumn{5}{|c|}{ Equation 6} \\
\hline 0.0025 & 0.01 & 7.065 & 7. 063 & 7.062 \\
\hline .005 & .02 & 7.017 & 7. 016 & 7.014 \\
\hline .01 & .04 & 6.959 & 6. 956 & 6.953 \\
\hline .0125 & .05 & 6.937 & 6.934 & 6.931 \\
\hline .025 & .10 & 6.862 & 6.855 & 6.849 \\
\hline .0375 & .15 & 6.811 & 6.803 & 6.794 \\
\hline .05 & .20 & 6.773 & 6. 762 & 6.752 \\
\hline .0625 & .25 & 6. 742 & 6. 729 & 6.717 \\
\hline \multicolumn{5}{|c|}{ Equation 7} \\
\hline .0025 & 0.01 & 7.066 & 7.065 & -.... \\
\hline .005 & .02 & 7.019 & 7. 020 & -... \\
\hline .01 & .04 & 6. 962 & - n. & -.... \\
\hline .0125 & .05 & 6. 942 & 6.944 & -.... \\
\hline .025 & .10 & 6.873 & 6. 873 & 6.876 \\
\hline .0375 & .15 & 6.830 & 6.829 & 6.834 \\
\hline .05 & .20 & 6. 796 & 6. 796 & 6.802 \\
\hline .0625 & .25 & 6.774 & 6. 774 & 6. 781 \\
\hline
\end{tabular}

${ }_{3}^{3}$ The last two terms of eq 6 represent $-\log \left(f_{\mathrm{H}_{2} \mathrm{PO}_{4}} / f_{\mathrm{HPO}_{4}}\right)^{\circ}$. It is evident by comparison with eq 5 that this method of evaluating paH sets $\log f_{\mathrm{X}}^{\circ}$ equal to $-0.5085 \sqrt{\mu} /\left(1+0.3281 a^{\circ} \sqrt{\mu}\right)$, without a term linear in ionic strength. decrease of the latter quantity with increasing atomic weight of the halogen has not been compensated; indeed paH shows a slightly larger decrease than does $-\log \left(f_{\mathrm{H}} f_{\mathrm{X}} m_{\mathrm{H}}\right)^{\circ}$ at the same ionic strength. A part of the difficulty is associated with the two-parameter form of eq 5 . If a small systematic change, within experimental error, were made in $\log f_{r}^{\circ}$, significant changes in $a^{\circ}$ and $\beta^{\circ}$ of a compensatory nature might be necessary to afford the best fit of the data to eq 5. For example, $a^{\circ}=4.0$ and $\beta^{\circ}=0.079$ reproduce $\log f_{r}^{\circ}$ for the iodide series with a mean deviation of 0.0003 . Yet the deviation would be only 0.0008 , or still considerably less than the uncertainty assigned to $\log f_{r}^{\circ}$, if 4.4 and 0.135 were chosen as the correct set of parameters. If the latter values gave the best fit, however, the paH computed from the iodide series would be 0.006 unit higher at an ionic strength of 0.25 . In other words, these changes in the two parameters do not offset one another in the calculation of paH. Measurements at ionic strengths above 0.25 , which are of most use in fixing accurate values of the parameters, are lacking here.

If the activity-coefficients of the three halide ions in the phosphate solution were assumed to equal the mean activity coefficients of the corresponding halogen acids, after the suggestion of Guggenheim [16], and these mean activity coefficients were set equal to their values in pure solutions of $\mathrm{HX}$ $[11,17,18]$ at the appropriate ionic strengths, paH could be evaluated:

$$
\begin{aligned}
\mathrm{paH}=-\log \left(f_{\mathrm{H}} f_{\mathrm{X}} m_{\mathrm{H}}\right)^{\circ}+\log f_{\mathrm{X}}^{\circ} \equiv \\
-\log \left(f_{\mathrm{H}} f_{\mathrm{X}} m_{\mathbf{H}}\right)^{\circ}+\log f_{\mathrm{HC} 1}
\end{aligned}
$$

The results of this calculation are given in the second half of table 6 . The agreement among the three sets of values is improved, but the $\mathrm{paH}$ is higher than before. The activity coefficient of hydrochloric acid is lowered by potassium ions [19] and sodium ions [20]. Hence, paH computed in this manner is understandably too high.

The $\mathrm{paH}$ calculated from $\mathrm{p} K$ or from - log $\left(f_{\mathrm{H}} f_{\mathrm{X}} m_{\mathrm{H}}\right)^{\circ}$ will approach - $\log \mathbf{a}_{\mathrm{H}}$ in dilute solutions, where all reasonable assumptions relating the ionic activity coefficients yield substantially equivalent results. In the region of higher ionic strengths, the paH value must be considered a unit on an arbitrary scale. 


\section{References}

[1] R. G. Bates and S. F. Acree, J. Research NBS 34, 373 (1945) RP1648.

[2] W. J. Hamer, G. D. Pinching, and S. F. Acree, J. Research NBS 36, 47 (1946) RP1690.

[3] G. G. Manov, N. J. DeLollis, P. W. Lindvall, and S. F. Acree, J. Research NBS 36, 543 (1946) RP1721.

[4] S. P. L. Sørensen and K. Linderstrøm-Lang, Compt. rend. trav. lab. Carlsberg 15, No. 6 (1924).

[5] D. A. MacInnes, Cold Spring Harbor Symposia on Quant. Biol. 1, 190 (1933).

[6] J. Sendroy, Jr., Trans. Electrochem. Soc. 74, 595 (1938).

[7] R. G. Bates and S. F. Acree, J. Research NBS 30, 129 (1943) RP1524.

[8] A. S. Keston, J. Am. Chem. Soc. 57, 1671 (1935).

[9] R. G. Bates, J. Am. Chem. Soc. 60, 2983 (1938).
[10] R. G. Bates, G. L. Siegel, and S. F. Acree, J. Research NBS 30, 347 (1943) RP1537.

[11] H. S. Harned and R. W. Ehlers, J. Am. Chem. Soc. 55, 2179 (1933).

[12] B. B. Owen and L. Foering, J. Am. Chem. Soc. 58, 1575 (1936).

[13] B. B. Owen, J. Am. Chem. Soc. 57, 1526 (1935).

[14] R. K. Gould and W. C. Vosburgh, J. Am. Chem. Soc. 62, 1817 (1940).

[15] E. Hückel, Physik. Z. 26, 93 (1925).

[16] E. A. Guggenheim, J. Phys. Chem. 34, 1758 (1930).

[17] H. S. Harned, A. S. Keston, and J. G. Donelson, J. Am. Chem. Soc. 58, 989 (1936).

[18] H. S. Harned and R. A. Robinson, Trans. Faraday Soc. 3\%, 302 (1941).

[19] H. S. Harned and W. J. Hamer, J. Am. Chem. Soc. 55, 2194 (1933).

[20] H. S. Harned, J. Am. Chem. Soc. 5\%, 1865 (1935).

Washington, May 12, 1947. 